\title{
O Acesso direto dos indivíduos ao Comitê de Direitos Econômicos, Sociais e Culturais da ONU*
}

\section{The access of individuals to the Committee on Economic, Social and Cultural Rights}

Renato Zerbini Ribeiro Leão'

\section{Resumo}

A origem da Organização das Nações Unidas está fortemente conectada e influenciada pelo final da Segunda Guerra Mundial e pela ideologia de seus vencedores. Os cinco grandes países, que representavam claramente as duas ideologias diametralmente opostas fincadas no seio da ONU, marcaram a divisão precipitada e imprudente dos direitos humanos em civis e políticos, por um lado, em econômicos, sociais e culturais, por outro. Com o depósito do $10^{\circ}$ instrumento de ratificação, o Protocolo Opcional ao Pacto Internacional de Direitos Econômicos, Sociais e Culturais entrou em vigência em 5 de maio de 2013, mais de 60 anos depois que a Declaração Universal de Direitos Humanos prometera a universalidade, indivisibilidade e complementaridade desses direitos.

Palavras-chaves: ONU. Direitos humanos. Acesso direto do indivíduo. Pacto Internacional de Direitos Econômicos. Sociais e Culturais.

\begin{abstract}
The origin of the United Nations Organization is strongly intertwined with and influenced by the ending of the Second World War and by its winners' ideologies. The five great countries, that represented clearly two opposing ideological chains diametrically rooted at the core of the UNO, would mark the precipitated and imprudent division of human rights into civil and political rights, on the one hand, and economic, social and cultural rights, on the other hand. With the deposit of the $10^{\text {th }}$ ratification instrument the Optional Protocol of the International Covenant on Economic, Social and Cultural Rights entried into force on 5 May 2013, more than sixty years that the Universal Declaration of Human Rights promised universality, indivisibility and complementarity for all these rights.
\end{abstract}

Keywords: UN. Human rights. Access of individuals. International Covenant on Economic. Social and Cultural Rights.

* Recebido em: 12/04/2013

Aprovado em: 17/05/2013

1 PhD em Direito Internacional e Relações Internacionais. Professor Universitário de Direito Internacional Público, Política Internacional e as Três Vertentes da Proteção Internacional da Pessoa Humana em Brasília no UniCEUB. Membro do Comitê de Direitos Econômicos, Sociais e Culturais da Organização das Nações Unidas (CDESC). Email: rzrleao@uol.com.br 


\section{A origem das Nações Unidas e os Direitos Hu- manos}

A origem das Nações Unidas ${ }^{1}$ está fortemente vinculada e influenciada pelo final da Segunda Guerra Mundial e pela ideologia de seus vencedores. Em consequência, seu Conselho de Segurança (CSONU), desde sua criação, esteve sob influência dos ideais desses países vencedores. Ancorado nestes cinco principais países, (Estados Unidos da América do Norte, Inglaterra, França, China e a, então, URSS), ${ }^{2}$ o CSONU refletia o ideal político, social, econômico e militar de cada uma dessas potências. Dentro de suas paredes, simbolizava um palco para o duelo entre as grandes democracias ocidentais e os países da Europa socialista.

Os cinco grandes países, que representavam claramente duas correntes ideológicas opostas fincadas diametralmente no seio da ONU, marcariam a divisão precipitada e imprudente dos direitos humanos em civis e políticos, por um lado, e econômicos, sociais e culturais, por outro. Uma, ovacionando as liberdades de expressão, pensamento e religião, as liberdades individuais em geral, cultuando o neoliberalismo como o caminho inquestionável do cenário econômico mundial; a outra, ainda que contrária aos direitos humanos em um primeiro momento, defendendo os pilares socialistas, propondo direitos de extrema importância, como é o caso do princípio da igualdade (ou seja, a proibição de discriminações fundadas em raça, cor, sexo, língua, religião, opinião política, nacionalidade, propriedade etc.), direito de associação, direito a autodeterminação dos povos coloniais, dentre outros.

A União Soviética era contrária à discussão dos Direitos Humanos, não só pelo autoritarismo do governo estalinista, mas também pelo peso do pensamento marxista. O conceito tradicional dos Direitos Humanos, formado na tradição jusnaturalista, assenta-se em três pilares (CASSESE, 1993, p. 39):

1. Esses Direitos são inerentes à pessoa humana e prescindem de qualquer reco- nhecimento positivo (existem inclusive quando negados pelo Estado).

2. A ordem natural que os sustenta é válida em todas as partes e é imutável, prescindindo do contexto social do indivíduo.

3. Esses Direitos são próprios dos indivíduos enquanto tais, não dos grupos sociais.

Marx simplesmente rejeita esses três princípios e sustenta que os Direitos Humanos aclamados pela sociedade capitalista eram uma simples manifestação da burguesia; uma simples expressão das exigências dessa classe (CASSESE, 1993, p. 39). ${ }^{3}$ Nesse sentido, os direitos e as liberdades têm apenas um valor instrumental, servindo para subverter mais rapidamente a ordem existente. Contrariamente, esses valores já não servem na sociedade comunista porque esta realiza a integração entre o indivíduo e a comunidade. Marx proclamava que a justiça social e a dignidade humana traziam elementos que transcendiam as fronteiras dos Estados como a consciência social de se fazer parte de uma classe trabalhadora onde quer que se esteja. Ou seja, a doutrina dos Direitos Humanos estava em conflito com a ideologia e a prática na URSS. ${ }^{4}$

Portanto, a ordem internacional em 1945, época do nascimento da Organização das Nações Unidas, apresentava o domínio dos EUA no ocidente, tanto no plano militar e econômico, como na confirmação de um modelo cultural vigoroso que ganhava uma esplêndida difusão mundial. Na Europa do Leste, Stalin, colhendo os frutos da vitória, faz da URSS a segunda potência do planeta, expandindo o regime soviético aos países daquela região

3 Entretanto, especialmente o jovem Marx enfatiza a noção de "emancipação humana", em si mesma compatível com a noção filosófica de liberdade humana abrangida pela filosofia do direito natural. Um exemplo é a seguinte passagem da "Questão Judaica”: "A emancipação humana somente está completa quando o homem real, individual, tiver absorvido em si mesmo o cidadão abstrato; quando um homem individual, na sua vida cotidiana, no seu trabalho e em suas relações tiver se tornado um ser da espécie [...]" In: TUCKER, Robert C. (Org.) (THE, 1978, p. 46).

4 Cassese (1993) sustenta que, apesar do debate ideológico das potências da época, não se pode esquecer o enorme aporte libertador do pensamento de Marx no campo dos direitos econômicos e sociais, ademais da contribuição geral à teoria dos direitos humanos proporcionada pelo "revisionismo" marxista. 
(KENNEDY, 1989). ${ }^{5}$ Por outro lado, a decadência dos impérios coloniais e a emergência de novas superpotências estabelecem as raízes da descolonização e a aparição do então chamado Terceiro Mundo. ${ }^{6}$

Nesse contexto, formatava-se o cenário de discussões político-diplomáticas na ONU, assim como se construía o caminho do desenvolvimento, realização e aprovação da Declaração Universal dos Direitos Humanos e dos Pactos Internacionais de Direitos Civis e Políticos e de Direitos Econômicos, Sociais e Culturais, que, juntos, compõem a Carta Internacional de Direitos Humanos.

O Preâmbulo da Declaração Universal dos Direitos Humanos (DUDH), também influenciado pela realidade histórica e política de então, pugna pela afirmação do indivíduo como sujeito do Direito Internacional Público (DIP). Trata-se, portanto, de construção factual e jusfilosófica consubstanciadora de uma ideia fincada a partir de uma lógica sequencial sustentada nos sujeitos contemporâneos do DIP: os Estados, as Organizações Internacionais e os Indivíduos. Isto é, os Estados, mediante a celebração de um tratado internacional, criam as Organizações Internacionais, em cujo cerne e à luz do patrocínio dos Estados, facilitam o surgimento dos tratados internacionais de direitos humanos, dos quais emerge o indivíduo como um sujeito de DIP, capaz de demandar seus Estados por violação a uma das normas de um tratado internacional de direitos humanos. Trata-se, inclusive,

\footnotetext{
5 "Assim as exigências externas e internas da Guerra Fria podiam alimentar-se mutuamente, disfarçadas ambas pelo recurso aos princípios ideológicos. Liberalismo e comunismo, sendo idéias universais, eram mutuamente exclusivos; isso permitia a cada um dos lados compreender, e retratar, todo o mundo como uma arena na qual a luta ideológica não se podia separar da vantagem política e de poder. Ou se estava com o bloco liderado pelos americanos, ou com o bloco soviético. Não havia meio-termo; na era de Stalin e Joe McCarthy, era imprudente pensar que pudesse haver. Era essa a realidade estratégica, a que não apenas os povos de uma Europa dividida, mas também os da Ásia, Oriente Médio, África, América Latina e outros teriam de ajustar-se." (KENNEDY, 1989, p. 356).

6 Kennedy (1989) assim explicava o terceiro mundo: "O desmoronamento [...] dos impérios no Extremo Oriente depois de 1941, a mobilização das economias e o recrutamento de mão-de-obra de outros territórios dependentes, durante a guerra, as influências ideológicas da Carta do Atlântico, e o declínio da Europa - tudo isso se combinou para liberar as forças de transformação no que, na década de 1950, foi chamado de terceiro mundo. [...] Mas ele era descrito como 'terceiro' mundo precisamente porque insistia na sua distinção dos blocos dominados pelos americanos e pelos russos." (KENNEDY, 1989, p. 375).
}

de um processo que se retroalimenta. Consequentemente, poderia afirmar que o Preâmbulo da DUDH ilustra a consagração política da passagem de uma sociedade internacional, sobretudo desde a óptica do DIP, de viés estatocêntrica, para uma sociedade internacional que reposiciona o indivíduo no epicentro de suas discussões. ${ }^{7}$ Na sociedade internacional do Século XXI, a subjetividade internacional do indivíduo é uma realidade institucionalizada no DIP.

Com esse reposicionamento emergem os grandes documentos e tratados internacionais de direitos humanos. Ademais, a partir da consolidação da ONU e da Carta Internacional de Direitos Humanos, todas as constituições nacionais promulgadas a continuação carregaram consigo as normas, os princípios e os valores constantes desses instrumentos internacionais de salvaguarda da dignidade humana. Positivava-se, desse modo, a maioria dos direitos humanos. Vale dizer, grande parte dos direitos humanos se consubstanciava em direitos fundamentais. À luz do rigor voluntarista do DIP, os direitos fundamentais nada mais são do que os direitos humanos plasmados nas normas dos tratados internacionais e das constituições dos Estados (LEÃO, 2009, p. 37-39).

\section{A afirmação dos direitos humanos na Organi- zação das Nações Unidas}

A organização das Nações Unidas foi criada durante a Conferência de San Francisco, realizada entre os dias 25 de abril e 26 de junho de 1945, nos EUA. A Carta das Nações Unidas (ou Carta de San Francisco) foi firmada em 26 de junho de 1945 e entrou em vigor em 24 de outubro daquele mesmo ano. Foi então ratificada pela URSS, EUA, China, Reino Unido e França - as cinco potências - e pela maioria dos estados fundadores da Organização Internacional, participantes da Conferência. ${ }^{8}$

Notou-se, desde que se efetivou a criação da ONU, ${ }^{9}$ a formação de quatro aglomerações bem definidas que

7 Sobre isso consultar: Trindade (2005).

8 São membros originários da ONU aqueles Estados que firmaram e ratificaram a Carta das Nações Unidas, logo depois da participação na Conferência de São Francisco ou, pelo menos, firmaram a Declaração das Nações Unidas de 1942.

9 No momento de sua criação, os membros da ONU eram 58: 14 ocidentais, 20 latino-americanos, 6 socialistas, 4 africanos e 14 asiáticos. 
mantinham forte influência nas discussões, desenvolvimento e formação da doutrina dos direitos humanos em seu seio. Um grupo de países ocidentais, que rapidamente tomaram a liderança política da instituição e tinham nos Estados Unidos, na França e na Inglaterra, seus mentores políticos e ideológicos, seguidos por muitos outros países do Ocidente político, entre os quais figurava a Austrália. Um segundo bloco formado pelos países da América Latina que agarraram, desde o início, a causa dos direitos humanos, tomando muitas vezes, nesse campo, decisões mais avançadas que a dos próprios países mais desenvolvidos do hemisfério. O bloco dos países socialistas, em conformidade com seus princípios e ideias, dotados de extremo cuidado político e desconfiança generalizada, aceitou colaborar no avanço dos direitos humanos. E os países asiáticos, com exceção dos muçulmanos dirigidos pela Arábia Saudita e pelo Paquistão, tiveram pouca presença nas discussões iniciais da matéria. ${ }^{10}$

Apesar das quatro aglomerações supracitadas, o grosso do confronto político e ideológico deu-se entre o Ocidente e a Europa socialista. Tal fato é verificável por meio dos debates travados durante os anos em estudo (1945-1966) e confirmado pela composição encarregada de conciliar e elaborar as diferentes propostas e teses que brotaram das discussões. O Comitê de Redação, composto principalmente por membros da corrente ocidental e pela URSS, estava assim constituído: Austrália, Chile, EUA, França, Grã- Bretanha, Líbano e URSS.

As discussões então travadas nas Nações Unidas encarnavam o contexto político e diplomático da GuerraFria. ${ }^{11} \mathrm{~A}$ Carta das Nações Unidas, no que diz respeito aos direitos humanos, contemplava dispositivos bem distantes das expectativas e esperanças que haviam sido suscitadas pela declaração do Presidente Roosevelt, de 1941. De fato, cada uma das potências vitoriosas da II GM trazia, no momento de redação da Carta, problemas no campo dos direitos humanos. Nos EUA, a discriminação racial; e na URSS, a falta de liberdade e expressão política.

Os dispositivos da Carta de San Francisco não permitem uma definição clara e precisa dos direitos humanos. O documento limita-se a mencionar a promoção e/ou

${ }^{10}$ Sobre o assunto, ler: Cassese (1993, p. 40-46).

${ }^{11}$ Clima político-ideológico instaurado no cenário mundial imediatamente depois de terminada a II Grande Guerra, por parte das duas maiores potências do momento: EUA e URSS. desenvolvimento desses direitos, considerados como uma das metas da ONU, juntamente ao seu outro grande objetivo: a manutenção da paz e segurança internacionais. ${ }^{12}$

A relevância precípua e histórica da Carta de San Francisco, desde a perspectiva do Direito Internacional Público, salta na positivação dos princípios gerais que regem as relações amistosas entre os Estados. Estes estão iluminados ao longo dos artigos primeiro e segundo: a igualdade soberana dos Estados; a não intervenção nos assuntos internos dos Estados; proibição do uso ou ameaça da força; solução pacífica de controvérsias; igualdade de direitos e autodeterminação; cooperação internacional; direitos humanos; e boa-fé no cumprimento das obrigações internacionais. ${ }^{13}$ A Carta da ONU é o primeiro grande documento internacional universal que os registra de maneira tão explícita. Esses são os princípios gerais do Direito Internacional Público Contemporâneo.

\section{A carta internacional dos direitos humanos}

A Carta Internacional de Direitos Humanos é um conjunto de documentos conformado pela Declaração Universal de Direitos Humanos (DUDH), pelo Pacto Internacional de Direitos Civis e Políticos (PIDCP), pelo Pacto Internacional de Direitos Econômicos Sociais e Culturais (PIDESC) e por seus protocolos e documentos adicionais. Em 1945, o mundo marcava-se claramente dividido em duas correntes político-ideológicas que direcionavam o sistema internacional a girar em torno de uma natureza bipolar, comandada pelos EUA, por um lado, e pela URSS, por outro.

Os EUA guiavam os países capitalistas ocidentais, defendendo a democracia liberal como o único regime político capaz de promover o respeito às liberdades e aos direitos fundamentais, e o pleno desenvolvimento dos indivíduos, tanto do ponto de vista econômico quanto político. A URSS comandava o bloco socialista que tinha, na democracia social ou real, ${ }^{14}$ a chave para a eliminação das desigualdades sociais e o meio para o estabelecimento da

${ }^{12}$ Vide Art. $1^{\circ}$ da Carta das Nações Unidas.

${ }^{13}$ Sobre estes consultar: Trindade (2002, p. 91-140).

${ }^{14}$ Com relação à discussão a respeito de "democracia e socialismo", ler o verbete “Democracia”. In: BOBBIO, N. et al. (1992, p. 324-325). 
paz universal, já que países socialistas não disputariam guerras entre si. ${ }^{15}$

O informe da Comissão Preparatória das Nações Unidas de 1945 foi o que recomendou originariamente a criação de uma comissão de direitos humanos, para redigir uma declaração internacional de direitos. A conclusão desse documento, a quarta e última etapa na obra de criação da ONU, teve, como nas três etapas anteriores (QUINTANA, 1999, p. 69):

1. Aprovação das propostas do Plano de Dumbarton Oaks (adotadas em 1944) completadas por decisões tomadas na Conferência de Yalta (fevereiro de 1945).

2. Firma da Carta das Nações Unidas em San Francisco, que cria a ONU e institui a Comissão Preparatória (26 de junho de 1945).

3. Reuniões de Londres (a partir de 16 de agosto de 1945) patrocinadas pelo Comitê Executivo dessa Comissão, encarregada de elaborar o informe.

O documento da Comissão Preparatória relativo ao Conselho Econômico e Social (ECOSOC) estabelecia, em seu capítulo III, Seção 4, parágrafos 14 e 16, a criação da Comissão de Direitos Humanos, cujas atividades deveriam estar orientadas para uma declaração internacional de direitos humanos.

Foi na Primeira Sessão do Conselho Econômico e Social que se criou, por meio da Resolução 5 (I) de 16 de fevereiro de 1946, a Comissão Nuclear de Direitos Humanos, a qual foi formada por nove membros designados com base em sua capacidade pessoal. ${ }^{16}$

Depois de distintas argumentações e opiniões políticas acerca do tema, a Comissão de Direitos Humanos

\footnotetext{
${ }^{15}$ Sobre a temática tratada neste parágrafo, ler Wight (2002, p. 175-192).

${ }^{16}$ Seus membros originários eram Paal Berg (Noruega), René Casin (França), Fernand Dehousse (Bélgica), Victor Raúl Haya de la Torre (Peru), K.C.Neogi (Índia), Sra. Roosevelt (EUA), Jhon C.H. Wu (China), e também por pessoas que os membros do ECOSOC, representando URSS e Iugoslávia, designariam ao Secretário Geral da ONU. Posteriormente, C. L. Hsia substitui a C. H. Wu, como representante de China; e D. Brkish e A. Borisov representam a Iugoslávia e URSS, respectivamente.
}

reuniu-se pela primeira vez, entre os dias 27 de janeiro e 10 de fevereiro de 1947, em Lake Success. Nessa sessão, lhe foi encomendada, com a ajuda do Secretariado das Nações Unidas, a elaboração de um projeto preliminar da Declaração Internacional de Direitos Humanos, a ser submetido à discussão e à aprovação de todos os integrantes da Comissão na Sessão seguinte, de dezembro de 1947. Por não haver sido adotada devida repartição geográfica na eleição dos membros do Grupo de Redação, essa decisão foi alvo de críticas por parte do ECOSOC, e o procedimento para a elaboração do projeto foi modificado, de acordo com a Resolução 46 (IV) do ECOSOC, de 28 de março de 1947.

Um novo Comitê, com base em uma repartição geográfica mais equitativa, foi nomeado e reuniu-se em Lake Success, de 11 de junho a 5 de julho de 1947, dando início aos trabalhos de redação. O Comitê adotou um anteprojeto de declaração de direitos preparado pelo Secretariado da ONU (Divisão de Direitos Humanos da Secretaria Geral, presidida pelo jurista canadense John P. Humprey), composto de um preâmbulo e 48 artigos. ${ }^{17}$

Segundo integrantes da Divisão de Direitos Humanos, a principal virtude do documento consistia na tentativa de "[...] dar uma resposta positiva ao interrogante de saber se era ou não possível chegar-se a um acordo sobre uma norma universal em matéria de direitos humanos" (QUINTANA, 1999, p. 76).

Uma longa e controversa discussão cercava a atmosfera da CDH e do Comitê de Redação. Jurisconsultos internacionais e cientistas sociais ampliavam o leque de discussões, baseados em distintos pensamentos ideológicos que se assentavam no cenário mundial, a suscitarem indagações e questionamentos acerca da liberdade do indivíduo perante as forças da coletividade, dos juízos de valor na sociedade industrial, do fundamento jusnaturalista dos direitos consagrados, da inclusão dos direitos econômicos e sociais na futura declaração de direitos, e até das relações entre direitos individuais e sociais, e de suas diferenças na implementação de cada categoria de direito ${ }^{18}$.

\footnotetext{
${ }^{17} \mathrm{O}$ documento continha quase todos os direitos mencionados em diversas constituições nacionais e outros dispositivos presentes no texto de declaração internacional em poder do Secretariado.

${ }^{18}$ Esta discussão e análise histórica vêm aprofundadas em Trindade (1997, p. 35-37).
} 
O trabalho de redação da futura Declaração não se interrompia. A partir de um primeiro documento elaborado por René Cassin e outros membros do Comitê, composto por um preâmbulo e 43 artigos, o Comitê de Redação submeteu à Segunda Sessão da Comissão de Direitos Humanos dois anteprojetos a fim de que que fossem discutidos e passados para uma versão final.

Durante a Segunda Sessão da Comissão de Direitos Humanos, ${ }^{19}$ ficou decidido ${ }^{20}$ denominar ao primeiro documento Declaração, ao segundo documento Pacto e ao conjunto Carta, isto é, a expressão Carta Internacional de Direitos Humanos seria dirigida à totalidade dos três documentos em preparação. Criaram-se três grupos de trabalho para o exame em separado dos documentos e, a partir dos informes desses grupos, a Comissão de Direitos Humanos elaborou dois textos, um para a declaração e outro para o pacto, que foram enviados aos governos para as devidas observações e sugestões.

Os dois documentos, a Declaração e o Pacto, com as devidas propostas dos governos, foram, então, revisados na Segunda Sessão do Comitê de Redação. ${ }^{21}$ A metodologia utilizada foi a da apreciação inicial do Pacto, seguida da análise dos dois outros documentos que comporiam a Carta Internacional. Tal processo não contou com o apoio dos representantes da URSS e do Líbano, que gostariam de examinar primeiramente a Declaração, ou seja, começar pelos princípios fundamentais, para depois, então, efetuar o estudo do Pacto e das medidas de aplicação. ${ }^{22}$

Durante a Terceira Sessão da Comissão de Direitos Humanos, realizada em Lake Success, de 24 de maio a 18 de junho de 1948, revisou-se apenas o projeto de Declaração, tomando em conta as emendas propostas pelos distintos representantes, não havendo tempo hábil para a apreciação do Pacto e das medidas de aplicação. A CIDH informou, em seu relatório ${ }^{23}$ ao ECOSOC, que a Comissão não havia concluído integralmente a sua obrigação, ou seja, faltava-lhe incluir o Pacto e as medidas de execução e/ou aplicação, propondo que essa tarefa deveria ser finalizada na Quarta Sessão da Comissão, em 1949.

\footnotetext{
${ }^{19}$ Acontecida em Genebra, de 12 a 17 de dezembro de 1947.

${ }^{20}$ Decidido a partir de uma proposta sírio-libanesa.

${ }^{21}$ Realizada em Lake Succes, de 3 a 21 de maio de 1948.

${ }^{22}$ A eleição interna no Comitê de Redação para a utilização da metodologia assinalada no texto deu-se por 5 votos a favor, 1 contra e 2 abstenções.

${ }^{23}$ O Relator era o representante do Líbano, Sr. Malik.
}

O ECOSOC enviou o projeto de declaração à Assembleia Geral, que incumbiu a sua Terceira Comissão, encarregada de assuntos sociais, humanitários e culturais (III CAG), de analisá-lo e formular propostas. A III CAG concluiu pelo estudo apenas da Declaração, entendendo que não estava em condições de fazer um exame mais profundo dos outros dois documentos. Ademais, aprovou a iniciativa do representante do Haiti (E. Saint-Lot), que estabeleceu o caráter universal do documento, bem como a emenda da França, que trocava a palavra "internacional" pelo termo "universal".

Assim, em 10 de dezembro de 1948, em sua Terceira Sessão Ordinária, a Assembleia Geral da ONU, reunida em Paris (Palais de Chaillot), por meio de sua Resolução 217 A (III), adotou a Declaração Universal de Direitos Humanos, que obteve 48 votos favoráveis, 8 abstenções e nenhum voto contra. ${ }^{24} \mathrm{~A}$ Declaração Universal legitimava a preocupação da sociedade internacional com a promoção e a proteção dos direitos humanos, condenando as violações maciças e persistentes, inclusive em conflitos armados, e elegendo a eliminação da pobreza extrema e da exclusão social prioridades internacionais. Portanto, tendo contraído essas obrigações perante a comunidade internacional, os Estados não poderiam, como tampouco podem atualmente, alegar que a matéria é de exclusiva jurisdição doméstica (RODRIGUES, 2000, p. 70).

A partir da proclamação da Declaração Universal dos Direitos Humanos, em 10 de dezembro de 1948, todos os países do mundo, inclusive aqueles que não atravessaram o largo processo histórico de formação do Estado liberal e democrático moderno, dispõem de um código internacional para decidir como se comportar e como julgar os demais. É um código que não só se aplica no âmbito universal, mas encerra também preceitos que têm valor em áreas anteriormente não tomadas em conta nas

\footnotetext{
${ }^{24}$ Votaram a favor: Birmânia, Canadá, Chile, China, Colômbia, Costa Rica, Cuba, Dinamarca, República Dominicana, Equador, Egito, El Salvador, Etiópia, França, Grécia, Guatemala, Haiti, Islândia, Índia, Irã, Iraque, Israel, Líbano, Luxemburgo, México, Países Baixos, Nova Zelândia, Nicarágua, Noruega, Paquistão, Panamá, Paraguai, Peru, Filipinas, Suécia, Síria, Turquia, Reino Unido, Estados Unidos da América, Tailândia, Uruguai, Venezuela, Afeganistão, Argentina, Austrália, Bolívia, Bélgica e Brasil. Abstenções: Bielo-Rússia, Checoslováquia, Polônia, Arábia Saudita, Ucrânia, África do Sul, União das Repúblicas Socialistas Soviéticas e Iugoslávia.
} 
Constituições dos Estados ocidentais. ${ }^{25}$ Diferentemente de outras épocas, na atualidade as normas internacionais proíbem qualquer "trato desumano ou degradante". Houve um tempo no qual a denúncia limitava-se a citar determinados governos, que descuidavam dos interesses da população; hoje, pode-se acusá-los de violar as normas internacionais, que preveem, por exemplo, o direito à alimentação, o direito à moradia digna, o direito ao meio ambiente sadio etc. (CASSESE, 1993, p. 7-57). No início do século XXI, impera o princípio de afirmação da dignidade humana.

Após a Carta de San Francisco ${ }^{26}$ e a Declaração Universal dos Direitos Humanos, todas as Constituições Nacionais proclamadas tiveram, com maior ou menor intensidade, o impacto de suas influências. Ademais, as Organizações Internacionais regionais - tais como o Conselho da Europa, a Organização dos Estados Americanos e a Unidade Africana - existem em coordenação absoluta com a ONU e a DUDH. Portanto, os Direitos Humanos estão necessariamente na órbita de todos esses entes de Direito Internacional Público.

Nota-se, assim, a existência de um verdadeiro regime universal de direitos humanos, cuja importância assenta-se na consolidação desse corpo extensivo de normas e de órgãos internacionais globalmente aceitados. Estes, independentemente de qualquer mecanismo de supervisão, contribuíram para empoderar os defensores dos direitos humanos ${ }^{27}$ e restringir determinadas ações de governos. De fato, em uma "sociedade quase justa existe uma aceitação pública dos mesmos princípios de justiça”" (RAWLS, 2008, p. 483). No Século XXI, tem-se a afirmação dos direitos humanos, sendo estes um princípio geral de Direito Internacional Público, como um dos pilares de uma efetiva justiça universal.

25 "A Declaração Universal dos Direitos Humanos não possui qualquer valor de obrigatoriedade para os Estados. Ela não é um tratado, mas uma simples declaração, como indica o seu nome. O seu valor é meramente moral. Ela indica as diretrizes a serem seguidas neste assunto pelos Estados. [...] De qualquer modo pode-se afirmar que atualmente há uma espécie de consenso em considerá-la um sistema internacional e, portanto, obrigatória." (MELLO, 2000, p. 823).

${ }^{26}$ Tratado internacional que deu origem a Organização das Nações Unidas (ONU), em vigência desde 24 de outubro de 1945.

${ }^{27}$ Sugestão de leitura: Leão (2010, p. 249-271).
Em consequência, se na contemporaneidade existe uma crise universal, esta não é simplesmente uma crise dos Estados ou dos seus valores, trata-se de uma crise do ser humano mesmo e que só ele poderá superar, pois ainda que muitos tenham se esquecido, foi o Estado criado pelo ser humano como forma de organização social e não o contrário. Em consequência, os Direitos Humanos não desaparecerão por fazer-se respeitar por meio de suas normas oriundas do Direito Internacional Público e do multilateralismo. O risco do menoscabo das normas de Proteção Internacional da Pessoa Humana ${ }^{28}$ reside justamente no polo oposto da afirmação anterior; ou seja, será o abrandamento da normativa oriunda do Direito Internacional Público e das normas de convivência harmônica e pacífica entre os Estados ante a falsa retórica bélica e unilateral, esta última despossuída de qualquer razoabilidade humana, o fato capaz de fazer com que os Direitos Humanos retrocedam.

\section{Pacto Internacional de Direitos Econômi- cos, Sociais e Culturais (PIDESC)}

O PIDESC foi aprovado e aberto para a assinatura, ratificação e adesão em 16 de dezembro de 1966, pela Resolução 2.200 A (XXI) da Assembleia Geral da ONU. Finalmente, entrou em vigor em 3 de janeiro de 1976. Em 7 de março de 2013, são 160 os Estados Partes. ${ }^{29}$ É ele um dos pilares da Carta Internacional de Direitos Humanos.

As normas do PIDESC, a guisa de resumo, dispõem sobre: direito ao trabalho, direito a condições equitativas e satisfatórias de trabalho, direito a fundar e a se afiliar a sindicatos, direito à seguridade social, direito à proteção e a assistência à família, direito a um nível de vida adequado, direito ao mais alto nível possível de saúde física e mental, direito à educação, e direito à cultura e ao gozo dos benefícios do progresso científico. Estes, à luz dos princípios da livre determinação, da igualdade e da não discriminação.

\footnotetext{
${ }^{28}$ Compreende: o Direito dos Conflitos Armados (Direito Humanitário), Direitos Humanos e Direito dos Refugiados.

${ }^{29}$ Disponível em: <http://treaties.un.org/Pages/ViewDetails. aspx?src=TREATY\&mtdsg_no=IV-3\&chapter=4\&lang=en $>$. Acesso em: 7 mar. 2013.
} 


\subsection{O Comitê de Direitos, Econômicos, Sociais e Cul- turais (CDESC)}

O CDESC é um órgão internacional do sistema ONU que está conformado por 18 especialistas independentes e monitora a implementação, pelos seus Estados Partes, do PIDESC. Ele foi estabelecido pelo ECOSOC, por meio de sua Resolução 1.985/17 de 28 de maio de 1985.

Todos os Estados Partes no PIDESC estão obrigados a submeter informes regulares ao CDESC sobre a implementação desses direitos, sendo que seus primeiros informes devem ser rendidos a cabo dos dois primeiros anos da vigência do PIDESC, e depois, a cada cinco anos, deverão encaminhar seus informes de seguimento àquele primeiro informe. O CDESC examinará cada informe e endereçará suas preocupações e recomendações aos Estados Partes na forma de "observações conclusivas".

O CDESC reúne-se em Genebra, normalmente em dois períodos de sessões ao ano. Nestas, costumam-se haver uma sessão plenária de três semanas e um grupo de trabalho anterior ao seguinte período de sessões com duração de uma semana. O CDESC também adota sua interpretação das disposições do PIDESC, em formas de comentários gerais, bem como emite cartas e comunicados sobre os mais variados assuntos de importância capital para a afirmação dos DESC na seara internacional.

Até maio de 2013, o CDESC adotou 21 comentários gerais. No último, adotado em sua $43^{\mathrm{a}}$ sessão, realizada em novembro do ano de 2009, interpretou o direito de todo mundo a tomar parte na vida cultural conforme reza o Artigo 15, parágrafo 1.a do PIDESC. ${ }^{30}$ Nele diz que os direitos culturais são parte integrante dos direitos humanos e, igual aos demais, são universais, indivisíveis e interdependentes. Sua promoção e respeito cabais são essenciais para manter a dignidade humana; para a interação social positiva de indivíduos e comunidades em um mundo caracterizado pela diversidade e a pluralidade cultural.

O CDESC define a cultura como um conceito amplo e inclusivo que compreende todas as expressões da existência humana. A expressão "vida cultural" faz referência explícita ao caráter da cultura como um processo vital, histórico, dinâmico e evolutivo, que tem um

${ }^{30}$ Vide documento ONU. ECOSOC. E/C.12/GC/21/Ver. 1. passado, um presente e um futuro. Em consequência, o conceito de cultura não deve ser entendido como uma série de expressões isoladas ou compartimentadas, senão como um processo interativo pelo qual os indivíduos e as comunidades, mantendo suas particularidades e finalidades, dão expressão à cultura da humanidade. Esse conceito leva em conta a individualidade e a alteridade da cultura como criação e produto social.

O Comitê, por esse motivo, considera que a cultura abrange, entre outras coisas, as formas de vida, a linguagem, a literatura escrita e oral, a música e as canções, a comunicação não verbal, os sistemas de religião e de crenças, os ritos e as cerimônias, os esportes e jogos, os métodos de produção e a tecnologia, o entorno natural e o produzido pelo ser humano, a comida, o vestuário $\mathrm{e}$ a moradia, assim como as artes, os costumes e tradições, pelos quais indivíduos, grupos e comunidades expressam sua humanidade e o sentido dado a sua existência, configurando uma visão do mundo que representa seu encontro com as forças externas que afetam suas vidas. A cultura reflete e configura os valores do bem-estar e da vida econômica, social e política dos indivíduos, dos grupos e das comunidades.

Para o CDESC, a plena realização do direito de toda pessoa a participar da vida cultural requer a existência dos seguintes elementos, à luz da igualdade e da não discriminação: a) a disponibilidade é a presença de bens e serviços culturais que todo mundo possa desfrutar e aproveitar; b) a acessibilidade consiste em dispor de oportunidades efetivas e concretas para que os indivíduos e as comunidades gozem plenamente de uma cultura que esteja ao alcance físico e financeiro de todos, nas zonas urbanas e rurais; c) a aceitabilidade implica que as leis, políticas, estratégias, programas e medidas adotadas para o desfrute dos direitos culturais devem ser formulados e aplicados de tal forma que sejam aceitáveis para as pessoas e as comunidades; d) a adaptabilidade se refere à flexibilidade e pertinência das políticas, dos programas e das medidas adotadas em qualquer âmbito da vida cultural, respeitando a diversidade cultural das pessoas e comunidades; e) a idoneidade se refere à realização de um determinado direito humano de maneira pertinente e apta a determinado contexto ou a determinada modalidade cultural.

A importância desses comentários gerais assume especial relevância, na medida em que o CDESC não se 
furtou a opinar sobre questões centrais da exigibilidade dos DESC. Segundo esse Comitê, a natureza das obrigações dos Estados Partes para com esses direitos comporta tanto as de resultado - pois todas elas conduzem a um objetivo único (buscar progressivamente a plena efetividade desses direitos) - como as de comportamento, cujo cumprimento requer a imediatez do compromisso de adotar medidas sem estar submetido a nenhuma condição. Ademais, a obrigação de adotar medidas abarca até o máximo dos recursos disponíveis. A expressão "recursos" refere-se tanto aos existentes dentro do Estado Parte, como aqueles disponibilizados pela cooperação internacional. ${ }^{31}$

O nono comentário, pelo qual o CDESC precisa o conteúdo do dever dos Estados em dar efetividade ao PIDESC, também é auspicioso. Com esse objetivo, o direito a um recurso efetivo não deve ser interpretado sempre e necessariamente no sentido de um recurso judicial. Os recursos administrativos também estão aí contemplados e devem ser acessíveis, não onerosos, rápidos e eficazes, inclusive contando com o direito último de apelação judicial resguardando esses procedimentos. ${ }^{32}$ Ademais, no parágrafo $9^{\circ}$ desse Comentário, o CDESC clama pela justiciabilidade de todos os direitos contidos no PIDESC e afirma que, "quando um direito reconhecido no Pacto não se possa exercer plenamente sem uma intervenção do Poder Judiciário, é necessário estabelecer recursos judiciais." ${ }^{33}$

\subsection{O protocolo facultativo ao PIDESC}

Com a ratificação pelo $10^{\circ}$ Estado do Protocolo Facultativo ao Pacto Internacional de Direitos Econômicos, Sociais e Culturais, os indivíduos, cidadãos desses 10 países, poderão oferecer denúncia individual por não cumprimento das normas do PIDESC ao Comitê de Direitos Econômicos, Sociais e Culturais (CDESC), seu órgão internacional de supervisão. Em curtas palavras, os DESC já são direta e individualmente exigíveis no sistema da Organização das Nações Unidas (ONU).

Essa possibilidade materializou-se em 5 de maio de 2013, três meses depois de que o Uruguai, $10^{\circ}$ país a ratificar o Protocolo Facultativo ao PIDESC, procedera,

\footnotetext{
${ }^{31}$ CESCR General comment 3. (General Comments). Comentário Geral no 3 .

${ }^{32}$ ONU. ECOSOC. Doc. E/C.12/1998/24, parágrafo $9^{\circ}$.

${ }^{33}$ ONU. ECOSOC.Doc.E/C.12/1998/24, parágrafo $9^{\circ}$, in fine. (tradução nossa).
}

conforme reza seu texto, ao depósito de sua ratificação. Nesse momento, ademais dos uruguaios, apenas os indivíduos da Argentina, da Bolívia, da Bósnia-Herzegovina, de El Salvador, do Equador, da Eslováquia, da Espanha, da Mongólia e de Portugal, são os que poderão usufruir dessa proteção internacional. Isso como consequência da realidade do direito internacional público de que os Estados somente se obrigam para com os tratados internacionais a partir de suas próprias vontades. E estes, por enquanto, foram os que assim quiseram.

O Protocolo Facultativo ao PIDESC é um tratado internacional unanimemente adotado pela Assembleia Geral da ONU em 10 de dezembro de 2008 (Resolução A/RES/63/117). Em 2009, ele foi aberto para a assinatura dos Estados Partes no PIDESC e, em 5 de fevereiro de 2013, alcançou seu décimo depósito. Este possibilita ao CDESC considerar comunicações individuais envolvendo assuntos relacionados aos Direitos Econômicos, Sociais e Culturais no contexto do PIDESC.

O CDESC, após várias sessões dedicadas a uma intensa e minuciosa análise de seus artigos, aprovou o regulamento do Protocolo Facultativo do PIDESC em sua $49^{\mathrm{a}}$ sessão, realizada em novembro de 2012. De pronto, importante destacar que seu $4^{\circ}$ artigo diz que as comunicações poderão ser apresentadas por pessoas ou grupos de pessoas que se encontrem sob a jurisdição de um Estado Parte e que aleguem ser vítimas de uma violação de qualquer dos direitos enunciados no PIDESC.

Ademais, $\mathrm{o} 7^{\circ}$ artigo do regulamento consagra na seara dos DESC uma importante ferramenta contemporânea de proteção internacional dos direitos humanos: as medidas provisórias de proteção. Por intermédio desse artigo, resta claro que o Comitê, uma vez recebida a denúncia de violação de um dos artigos do PIDESC por um de seus Estados Partes, poderá, em circunstâncias excepcionais e antes de tomar uma decisão sobre o mérito do caso, transmitir ao Estado Parte interessado, para seu exame urgente, petição no sentido de que se adotem as medidas provisórias que o CDESC considere necessárias para evitar um possível dano irreparável à vítima ou às vítimas da violação denunciada. Tudo isso, sem prejulgar a decisão que se tome sobre a admissibilidade ou o mérito da petição. Trata-se, indubitavelmente, de um mecanismo de afirmação da dignidade humana e de exigibilidade de direitos diante de pretensas arbitrariedades praticadas pelos Estados. 
Endereça-se, assim, um caminho originalmente equivocado no regime jurídico dos Direitos Humanos: não mais, apenas os Direitos Civis e Políticos podem ser diretamente invocados pelos indivíduos no sistema universal. Desde logo, os DESC também. Para tanto, os Estados devem ratificar o Protocolo Facultativo ao PIDESC. $\mathrm{O}$ acesso direto dos indivíduos à justiça internacional é uma condição essencial para a afirmação da universalidade, da indivisibilidade e da complementaridade dos direitos humanos. Finalmente, os direitos humanos são um todo harmônico, possuem dependência recíproca de maneira que se complementam em si mesmos, devendo ser protegidos pelos Estados em todas e quaisquer circunstâncias (LEÃO, 2012, p. 28).

\section{Referências}

ASH, Timothy Garton. "El mundo, siete años después". Jornal El País, Espanha, Seção Crónica: Opinión, 14 set. 2008.Disponívelem:http://elpais.com/diario/2008/09/14/ domingo/1221363031_850215.html. Acesso em marco de 2013.

BOBBIO, N. et al. Dicionário de Política. Brasília: EdUnB, 1992.

CASSESE, Antônio. Los derechos humanos en el mundo contemporáneo. Barcelona: Ariel, 1993.

Kennedy, Paul. Ascensão e queda das grandes potências: transformação econômica e conflito militar de 1500 a 2000. Rio de Janeiro: Campus, 1989.

LEÃO, Renato Zerbini Ribeiro. La construcción jurisprudencial de los Sistema Europeo e Interamericano de Protección de los Derechos Humanos en materia de Derechos Económicos, Sociales y Culturales. Porto Alegre: Núria Fabris, 2009.

LEÃO, Renato Zerbini Ribeiro. El rol de la sociedad civil organizada para el fortalecimiento de la protección de los derechos humanos en el siglo XXI: un enfoque especial sobre los DESC. Revista del Instituto Interamericano de Derechos Humanos, San José de Costa Rica, v. 51, p. 249271, 2010.
LEÃO, Renato Zerbini Ribeiro. O Brasil e a Convenção Ibero-Americana dos Direitos dos Jovens. Madrid: OIJ, UNFPA. 2012.

MELLO, C. D. de Albuquerque. Curso de Direito Internacional Público. Rio de Janeiro: Renovar, 2000.

ORGANIZAÇÃO DAS NAÇÕES UNIDAS. ECOSOC. E/C.12/GC/21/, 2009. Disponível em: http://www2.ohchr. org/english/bodies/cescr/comments.htm. Acesso em março de 2013

QUINTANA, Fernando. La ONU y la exégesis de los derechos humanos: una discusión teórica de la noción. Porto Alegre: UNIGRANRIO, 1999.

RAWLS, John. Uma teoria de justiça. 3. ed. São Paulo: Martins Fontes, 2008.

Rodrigues, Simone Martins. Segurança internacional e Direitos Humanos: a prática da intervenção humanitária no pós-guerra fria. Rio de Janeiro: Renovar, 2000.

THE Jewish Question. In: TUCKER, Robert C. (Org.). The Marx-Engels Reader. New York: W. W. Norton, 1978.

TRINDADE, Antônio Augusto Cançado. International law for humankind: towards a new Jus: Gentium General Course on Public International Law. Holanda: Ed. Brill; Martinus Nijhoff Ed.; Serie Hague Academy of International Law, 2010.

TRINDADE, Antônio Augusto Cançado. A Recta Ratio nos Fundamentos do Jus Gentium como Direito Internacional da Humanidade: discurso de posse na Academia Brasileira de Letras Jurídica - Cadeira n. 47. Belo Horizonte: Del Rey, 2005.

TRINDADE, Antônio Augusto Cançado. O Direito internacional em um mundo em transformação. Rio de Janeiro: Renovar, 2002.

TRINDADE, Antônio Augusto Cançado. O legado da Declaração Universal e o futuro da Proteção Internacional dos Direitos Humanos. In: AMARAL JÚNIOR, Alberto e PERRONE-MOISÉS, Cláudia (Org.). O Cinqüentenário da Declaração Universal dos Direitos do Homem. São Paulo: Edusp, 1999.

WIGHT, Martin. A Política do Poder. Brasilia: FUNAG, 2002. 